\title{
The contrastive hierarchy in phonology $y^{1}$
}

\author{
B. Elan Dresher
}

\section{Introduction}

Since Saussure's famous statement that "dans la langue il n'y a que des différences" (Saussure [1916] 1972: 166), ${ }^{2}$ the notion of contrast has been at the heart of linguistic theory. While it is relatively uncomplicated to determine whether or not two sounds are contrastive in a given language (though see Chomsky 1964), it is another matter to determine whether a given feature is contrastive in any particular situation. I will show that from the beginning phonologists have vacillated between two different and incompatible approaches to determining contrastiveness. Further, one of these approaches is provably untenable. The other is more promising, and in the second part of this paper I will look at some applications of it. Given the centrality of the issue, it is remarkable that it has received almost no attention in the literature. Recovering this missing chapter of phonological theory sheds new light on a number of old and new controversies over contrast in phonology.

\section{Extraction of contrasts via fully specified minimal pairs}

One approach to determining contrastiveness is based on pairwise comparisons of fully specified pairs of phonemes. For example, given segments $/ \mathrm{p} \mathrm{b} \mathrm{m/}$ as in (1a) and the binary features [voiced] and [nasal], /p/ and /b/ contrast with

1 I would like to thank the members of the project on Markedness and Contrast in Phonology in the Department of Linguistics at the University of Toronto for many kinds of help over the years, as well as the students in LIN 1221 in Fall 2001. This research was supported in part by grants 410-96-0842, 410-99-1309, and 410-2003-0913 from the Social Sciences and Humanities Research Council of Canada.

2 With reference specifically to speech sounds (Saussure 1972: 163), "Ce qui import dans le mot, ce n'est pas le son lui-même, mais les différences phoniques qui permettent de distinguer ce mot de tous les autres" [What is important in a word is not the sound itself, but the phonetic contrasts that allow us to distinguish this word from all the others]. 
respect to [voiced], /b/ and $/ \mathrm{m} /$ contrast with respect to [nasal], and $/ \mathrm{p} /$ and $/ \mathrm{m} /$ contrast with respect to both features. In the latter case it is not clear which of these features should be considered contrastive; in the case of $/ \mathrm{p} \mathrm{b} / \mathrm{and} / \mathrm{b} \mathrm{m} /$, however, there is clearly only one contrastive feature in each case. Let us define a minimal pair as two members of an inventory that are distinguished by a single feature. ${ }^{3}$ If we want to determine contrastive features starting from fully specified representations, it makes sense to focus on minimal pairs, because they reveal the contrasting features in the purest way. Pairwise comparison of the minimal pairs in (1a) yields the representations in (1b).

French /p b m/ (Martinet 1964: 64)

a. Full specification

\begin{tabular}{|l|ccc|}
\cline { 2 - 4 } \multicolumn{1}{c|}{} & $\mathrm{p}$ & $\mathrm{b}$ & $\mathrm{m}$ \\
\hline voiced & - & + & + \\
nasal & - & - & + \\
\hline
\end{tabular}

c. Redundancy rules for (b)

$[0$ voiced $] \rightarrow[+$ voiced $]$ b. Features distinguishing minimal pairs

\begin{tabular}{|l|ccc|}
\cline { 2 - 4 } \multicolumn{1}{c|}{} & $\mathrm{p}$ & $\mathrm{b}$ & $\mathrm{m}$ \\
\hline voiced & - & + & \\
nasal & & - & + \\
\hline
\end{tabular}

$[0$ nasal $] \rightarrow[-$ nasal $]$

These are essentially the contrastive specifications proposed by Martinet (1964: 64 ) in his discussion of how to contrastively specify the consonants of Standard French. The redundancy rules in (1c) then fill in the unspecified features at some point before or during phonetic implementation.

Extraction of contrastive features from fully specified minimal pairs was evidently also used by Trubetzkoy ([1939] 1969), especially in the first part of his book. For example, Trubetzkoy (1969: 68-9) writes that in Standard French, $d$ and $n$ "are the only voiced dental occlusives". This fact is apparent from the fully specified feature values shown in $(2 \mathrm{a}) .{ }^{4} \mathrm{He}$ observes further that "neither voicing nor occlusion is distinctive for $n$, as neither voiceless nor spirantal $n$ occur as independent phonemes". That is, Trubetzkoy understands a feature to be distinctive in a phoneme if there is another phoneme in the language that

3 This kind of featural minimal pair differs from the usual sense of "minimal pair" in linguistics, which is a pair of words that differ by a single phoneme: for example, sit and kit, or kick and kiss. Determination of word minimal pairs does not require us to identify in what way (i.e., with respect to which features) one phoneme is crucially distinguished from another; it is enough to know that they are different.

4 These features are inferred from Trubetzkoy's discussion. Trubetzkoy assumes that the place feature is multi-valued; in the table, $d n t=$ dental, $b i l=$ bilabial, $a l v=$ alveolar, and $d o r=$ dorsal. 
is identical except for that feature. This notion of contrastiveness is consistent with extraction of contrastive features from fully specified minimal pairs. Since there is no voiceless $n$ to make a minimal pair with $n$ based on voicing, and no fricative $n$ to make a minimal pair based on occlusion, it follows on this view that voicing and occlusion cannot be distinctive in $/ \mathrm{n} /$, as shown in (2b), where only specifications that are contrastive in this sense are retained.

(2) Some French consonants, bilateral oppositions (Trubetzkoy 1969: 68-69)

a. Full specifications

\begin{tabular}{|l|cccccccccc|}
\cline { 2 - 9 } \multicolumn{1}{c|}{} & $\mathrm{t}$ & $\mathrm{d}$ & $\mathrm{n}$ & $\mathrm{p}$ & $\mathrm{b}$ & $\mathrm{m}$ & $\mathrm{s}$ & $\mathrm{z}$ & $\mathrm{k}$ & $\mathrm{g}$ \\
\hline voiced & - & + & + & - & + & + & - & + & - & + \\
continuant & - & - & - & - & - & - & + & + & - & - \\
place & dnt & dnt & dnt & bil & bil & bil & alv & alv & dor & dor \\
nasal & - & - & + & - & - & + & - & - & - & - \\
\hline
\end{tabular}

b. Contrastive specifications via minimal pairs

\begin{tabular}{|l|cccccccccc|}
\cline { 2 - 9 } \multicolumn{1}{c|}{} & $\mathrm{t}$ & $\mathrm{d}$ & $\mathrm{n}$ & $\mathrm{p}$ & $\mathrm{b}$ & $\mathrm{m}$ & $\mathrm{s}$ & $\mathrm{z}$ & $\mathrm{k}$ & $\mathrm{g}$ \\
\hline voiced & - & + & & - & + & & - & + & - & + \\
continuant & & & & & & & & & & \\
place & dnt & dnt & dnt & bil & bil & bil & alv & alv & dor & dor \\
nasal & & - & + & & - & + & & & & \\
\hline
\end{tabular}

c. Determination of bilateral oppositions

\begin{tabular}{|c|c|c|c|}
\hline$\underline{\text { Pair }}$ & In common & $\underline{\text { Shared with }}$ & Opposition \\
\hline $\mathrm{t} \sim \mathrm{n}$ & {$[\mathrm{dnt}]$} & $\mathrm{d}$ & multilateral \\
\hline$t \sim d$ & {$[\mathrm{dnt}$, -nasal $]$} & - & bilateral \\
\hline $\mathrm{d} \sim \mathrm{n}$ & {$[\mathrm{dnt},+$ +voiced, - cont $]$} & - & bilateral \\
\hline $\mathrm{d} \sim \mathrm{b}$ & [+voiced, -nasal] & $\mathrm{g}$ & multilateral \\
\hline
\end{tabular}

This approach to determining contrastive features poses problems for one of Trubetzkoy's most fundamental concepts, the classification of oppositions into bilateral and multilateral. The members of a bilateral opposition are unique with respect to the set of features they share; in a multilateral opposition, the members do not share any set of features not also shared by at least one other member of the inventory. Further, when classifying an opposition as bilateral or multilateral, "Of course, only the phonologically distinctive properties are to be considered" (Trubetzkoy 1969: 68). However, Trubetzkoy cannot maintain this position, given his analysis of French. 
Notice in (2b), for example, that with respect to the contrastive features, /d/ and $/ \mathrm{n} /$ share only the feature [dental], and this is true also of $/ \mathrm{t} /$ and $/ \mathrm{d} /$. Thus, $/ \mathrm{t} / \sim / \mathrm{d} /$ and $/ \mathrm{d} / \sim / \mathrm{n} /$ ought to be classified as multilateral oppositions. Trubetzkoy believes, however, that both $/ \mathrm{t} / \sim / \mathrm{d} /$ and $/ \mathrm{d} / \sim / \mathrm{n} /$ form bilateral oppositions in French, though he presents no evidence that this is the case. Thus, he concedes that sometimes noncontrastive features must be considered in assessing if an opposition is bilateral, as shown in (2c), where redundant but necessary features are underlined.

To maintain the more principled view that only contrastive features are to be considered in classifying oppositions, Trubetzkoy could either give up the idea that both the $/ \mathrm{t} / \sim / \mathrm{d} /$ and $/ \mathrm{d} / \sim / \mathrm{n} /$ oppositions are bilateral, and/or adopt a different criterion for determining contrastive features. We will see that there are grounds for doing both of these; in later sections of his book, Trubetzkoy takes quite a different approach to determining whether an opposition is bilateral or multilateral.

Jakobson (1949) apparently took a similar approach to specification of the features of Serbo-Croatian. I say "apparently" because he does not state explicitly how he arrived at his specifications, but we can work backwards to infer what the method was. I present his specifications of oral and nasal stops (only features relevant to this example are included). The shaded squares are those that Jakobson leaves unspecified. They are precisely the specifications that do not distinguish between minimal pairs. ${ }^{5}$

Specifications of oral and nasal stops

\begin{tabular}{l|ccc|}
\cline { 2 - 4 } \multicolumn{1}{c|}{} & $\mathrm{p}$ & $\mathrm{b}$ & $\mathrm{m}$ \\
\cline { 2 - 4 } voicing & - & + & \\
nasality & & - & + \\
saturation & - & - & - \\
gravity & + & + & + \\
\cline { 2 - 4 } & & &
\end{tabular}

\begin{tabular}{|ccc|}
\hline $\mathrm{t}$ & $\mathrm{d}$ & $\mathrm{n}$ \\
\hline- & + & \\
& - & + \\
- & - & - \\
- & - & - \\
\hline
\end{tabular}
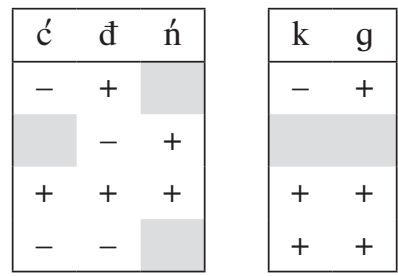

5 An exception is the specification of $/ \mathrm{m} /$ as [-saturation]. Since $/ \mathrm{m} \mathrm{n} n$ / are the only [+nasal] segments, the features [saturation] and [gravity] are needed only to distinguish between them. /n/ forms a minimal pair with /n'/ based on [saturation], and with $/ \mathrm{m} /$ based on [gravity]. As expected, $/ \mathrm{n} /$ is specified for both [saturation] and [gravity], and /n' is specified for [saturation] but not for [gravity]. By symmetry, /m/ ought to be specified for [gravity] but not for [saturation]. I suspect the specification of $/ \mathrm{m} /$ as [-saturation] is simply an error. I will show below that the minimal pairs method is not able to adequately distinguish all members of an inventory in the general case. Therefore, it is not surprising that Jakobson did not, or was not able to, adhere to it in a strict way. 
2.1. An algorithm for extracting contrasts via fully specified minimal pairs

Extraction of contrastive features from fully specified minimal pairs can be implemented by a formal algorithm. Such an algorithm was proposed by Archangeli (1988). I will call this the Pairwise Algorithm, given in (4):

(4) Pairwise Algorithm (Archangeli 1988)

a. Fully specify all segments.

b. Isolate all pairs of segments.

c. Determine which segment pairs differ by a single feature specification.

d. Designate such feature specifications as "contrastive" on the members of that pair.

e. Once all pairs have been examined and appropriate feature specifications have been marked "contrastive," delete all unmarked feature specifications on each segment.

An illustration of how this algorithm is supposed to work is given in (5). This is a typical five-vowel system characterized by the features [high], [low], and [back]. According to the Pairwise Algorithm, this five-vowel system, fully specified for these features as in (5a), would be underspecified as in (5b):

(5) Five-vowel system, features [high], [low], [back]

a. Full specifications

$\begin{array}{llllll} & \text { i } & \text { e } & \text { a } & \text { o } & \text { u } \\ \text { high } & + & - & - & - & + \\ \text { low } & - & - & + & - & - \\ \text { back } & - & - & + & + & +\end{array}$

b. Specifications according to the Pairwise Algorithm

$\begin{array}{lllllll} & \mathrm{i} & \mathrm{e} & \mathrm{a} & \mathrm{o} & \mathrm{u} & \text { Minimal pairs } \\ \text { high } & + & - & & - & + & \{\mathrm{i}, \mathrm{e}\} ;\{\mathrm{o}, \mathrm{u}\} \\ \text { low } & & & + & - & & \{\mathrm{a}, \mathrm{o}\} \\ \text { back } & - & - & & + & + & \{\mathrm{i}, \mathrm{u}\} ;\{\mathrm{e}, \mathrm{o}\}\end{array}$

\subsection{Problems with extracting contrasts via fully specified minimal pairs}

Deriving contrastive features from fully specified minimal pairs is unworkable for several reasons. First, it fails to adequately contrast segments that are not 
minimal pairs. Consider again example (1), French /p b m/. The contrastive specification in (1b) distinguishes $/ \mathrm{b} /$ from $/ \mathrm{p} /$ on one side and from $/ \mathrm{m} /$ on the other; but what about the contrast between $/ \mathrm{p} /$ and $/ \mathrm{m} /$ ? $/ \mathrm{p} /$ is [-voiced] and $/ \mathrm{m} /$ is [+nasal]; since these are not privative features but truly binary, we cannot conclude that the absence of a specification is necessarily distinct from a specification. Without running through the redundancy rules that tell us how to fill in missing specifications, we cannot decide if $/ \mathrm{p} /$ is distinct from $/ \mathrm{m} /$ or not. But then we have failed to arrive at a proper contrastive specification. Thus, the Pairwise Algorithm fails the Distinctness Condition proposed by Halle (1959), given in (6). Essentially, it says that 0 is not distinct from a plus or minus value in a binary feature system that is not privative. Examples are shown in (7).

(6) Distinctness of phonemes (Halle 1959: 32)

Segment-type $\{\mathrm{A}\}$ will be said to be different from segment-type $\{\mathrm{B}\}$, if and only if at least one feature which is phonemic in both, has a different value in $\{A\}$ than in $\{B\}$; i. e., plus in the former and minus in the latter, or vice versa.

(7) Examples of distinctness and non-distinctness (Halle 1959: 32)
a. $\{\mathrm{A}\}$ is not "different from" $\{\mathrm{C}\}$
b. All three are "different"

$\begin{array}{cccccccc} & \{\mathrm{A}\} & \{\mathrm{B}\} & \{\mathrm{C}\} & & \{\mathrm{A}\} & \{\mathrm{B}\} & \{\mathrm{C}\} \\ \text { Feature } 1 & + & - & + & \text { Feature 1 } & + & - & - \\ \text { Feature 2 } & 0 & + & - & \text { Feature 2 } & 0 & + & -\end{array}$

One can argue about whether contrastive specifications ought to meet the Distinctness Condition (I think they do, but Stanley (1967) is one of a number who disagree). However, the minimal pairs method faces much more severe problems of adequacy, in that there are common situations in which it fails by any measure to distinguish the members of an inventory. There are two types of cases in which this occurs.

First, the Pairwise Algorithm will fail when there are too many features relative to the number of phonemes in the inventory. The Pairwise Algorithm succeeds in distinguishing the five vowels in (5) in the three-dimensional feature space defined by the features [high], [low], and [back]. But recall that the Pairwise Algorithm starts from fully specified specifications; the limitation of the feature space to three features is arbitrary and unjustified. Full phonetic specification implies that the vowels be specified for all vowel features, including [round], [ATR], [nasal], and so on. Even adding just one more feature, say [round], causes the Pairwise Algorithm to fail to differentiate the five-vowel system in (5). The results are shown in (8). 
(8) Five-vowel system, features [high], [low], [back], [round] a. Full specifications

$\begin{array}{llllll} & \text { i } & \text { e } & \text { a } & \text { o } & \text { u } \\ \text { high } & + & - & - & - & + \\ \text { low } & - & - & + & - & - \\ \text { back } & - & - & + & + & + \\ \text { round } & - & - & - & + & +\end{array}$

b. Specifications according to the Pairwise Algorithm

$\begin{array}{lllllll} & \mathrm{i} & \mathrm{e} & \mathrm{a} & \mathrm{o} & \mathrm{u} & \text { Minimal pairs } \\ \text { high } & + & - & & - & + & \{\mathrm{i}, \mathrm{e}\} ;\{\mathrm{o}, \mathrm{u}\} \\ \text { low } & & & & & & \\ \text { back } & & & & & & \\ \text { round } & & & & & & \end{array}$

The only minimal pairs are $\{\mathrm{i}, \mathrm{e}\}$ and $\{\mathrm{o}, \mathrm{u}\}$; the addition of the fourth feature turns what used to be minimal pairs into segments that are distinguished by more than one feature. The features [back] and [round] are each redundant given the other, but one of them has to be retained. In such cases, the Pairwise Algorithm cannot decide which feature to keep and which to discard. It is not clear, then, that an approach to contrast that relies on minimal pairs can handle even the simplest inventories, once all features are taken into account.

In these situations there is a remedy available, and that is to reduce the number of features before employing the Pairwise Algorithm. But then some other mechanism must operate in advance of the Pairwise Algorithm to make the same kinds of decisions it should be making. We shall see that when we spell out what this other mechanism is, the Pairwise Algorithm will be shown to be superfluous.

There is another type of case in which the Pairwise Algorithm fails, and this does not involve extra features, but rather the way in which the members of an inventory are dispersed over the space defined by the feature set. That the Pairwise Algorithm gives a contrastive specification at all, whether correct or not, is due to the connectedness of the paths through the space defined by the set of features. We can model the space corresponding to the inventory in (5) and the minimal pair paths through it with a diagram as in (9). The four nodes in the left half of the diagram are [-back], the four on the right are [+back]; the top four nodes are [-low], the bottom four are [+low]; and the peripheral four nodes are [+high], the inner four are [-high]. An empty circle $\circ$ represents an unoccupied node, and $\mathrm{x}$ represents an impossible combination of [+high, +low]. The members of this inventory are distributed in such a way that every phoneme except /a/ has two neighbours, creating enough minimal pairs to produce a result. 
(9) Five-vowel system, features [high], [low], [back]

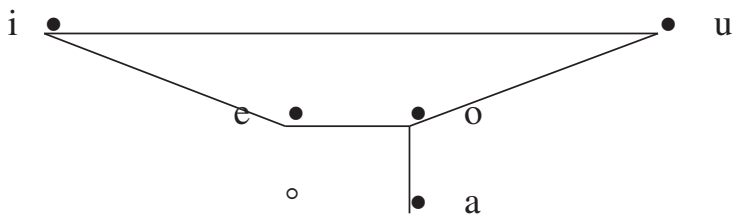

X

$\mathrm{X}$

Archangeli (1988) points out that not every five-vowel system can be assigned a contrastive set of specifications by the Pairwise Algorithm. An example of such an inventory is the vowel system of Maranungku (Tryon 1970), given in (10).

(10) Maranungku, features [high], [low], [back]

a. Full specifications

$\begin{array}{lccccc} & \text { i } & æ & \text { a } & \text { ə } & \text { U } \\ \text { high } & + & - & - & - & + \\ \text { low } & - & + & + & - & - \\ \text { back } & - & - & + & + & +\end{array}$

b. Specifications according to the Pairwise Algorithm

$\begin{array}{lllllll} & \text { i } & æ & \text { a } & \partial & u & \text { Contrasts } \\ \text { high } & & & & - & + & \{\partial, \mho\} \\ \text { low } & & & + & - & & \{a, \partial\} \\ \text { back } & - & - & + & & + & \{i, \mho\} ;\{æ, a\}\end{array}$

In this case, /i/ and /æ/ have the same contrastive specification because they occupy parallel positions in a contrast, as shown graphically in (11), but have no other neighbours that could further differentiate them in terms of this algorithm.

(11) Maranungku, features [high], [low], [back]

i

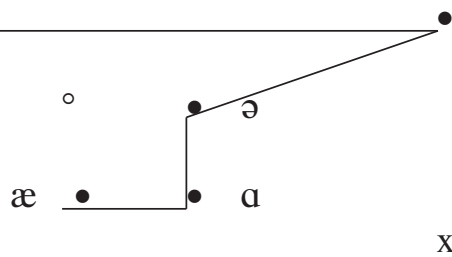

Whether or not an inventory has paths that make its members distinguishable by the Pairwise Algorithm is an accidental property, and should not be the basis of a theory of contrast. 


\section{Specification of contrasts by a hierarchy of features}

Another approach to contrast also has roots in the earliest work on contrast in phonology. In his discussion of the Polabian vowel system, Trubetzkoy (1969: 102-103) observes that a "certain hierarchy existed" whereby the back front contrast is higher than the rounded $\sim$ unrounded one, the latter being a subclassification of the front vowels. Trubetzkoy's rationale for this analysis is that the oppositions between back and front vowels are constant, but those between rounded and unrounded vowels of the same height are neutralizable (after $v$ and $j$ to $i$ and $\hat{e}$ ). Also, palatalization in consonants is neutralized before all front vowels, as well as before "the maximally open vowel a which stood outside the classes of timbre".

We can understand Trubetzkoy's remarks as suggesting that the feature [back] has wider scope than does [rounded]: [back] is relevant to all the vowels in the inventory, apart from a, whereas [rounded] has contrastive force only among the front vowels. Scope differences can be equally understood in terms of ordering: the feature [back] is ordered ahead of [rounded], notated as [back] $>$ [rounded]. Thus, the vowel inventory is divided on the basis of [back] before a contrast based on [rounded] is made. The statement that a "stood outside the classes of timbre" can be understood as implying that the feature that distinguishes a from all the other vowels, which we will here call [low], is ordered before all the other vowel features. The diagram in (12) gives a pictorial representation of the feature hierarchy suggested by Trubetzkoy's discussion. ${ }^{6}$

Polabian (Trubetzkoy 1969: 102-3): [low] > [back] > [rounded]

\begin{tabular}{|c|c|c|c|}
\hline \multicolumn{2}{|c|}{ Front } & \multicolumn{2}{|c|}{ Back } \\
\hline Unrounded & Rounded & & \\
\hline i & $\ddot{\mathrm{u}}$ & $\mathrm{u}$ & \\
\hline$\hat{\mathrm{e}}$ & $\ddot{o}$ & o & Nonlow \\
\hline $\mathrm{e}$ & & a & \\
\hline & & & Low \\
\hline
\end{tabular}

6 Trubetzkoy (1969: 103) further confirms that he does not consider rounding to be contrastive among the back vowels: "The properties of lip participation were phonologically irrelevant for the back vowels." This, despite the fact that the vowel he represents as a "appears to have been pronounced as a back vowel without lip rounding" (Trubetzkoy 1969: 210 n. 21). Presumably, he considered the contrastive distinction between this vowel and the other back vowels to be based on height rather than lip rounding. 
Elsewhere, Trubetzkoy (1969: 126) observes that Modern Greek has a bilabial stop /p/ and labiodental fricatives /f v/, and a postdental stop /t/ and interdental fricatives $/ \theta \mathrm{\partial} /$. Is the primary contrast one of occlusion (stop versus fricative) or of place? Trubetzkoy appeals to "parallel" relations between stops and fricatives at different places. In the sibilant and dorsal series (/ts s $\mathrm{z} /$ and $/ \mathrm{k} \mathrm{x} \mathrm{y} /$, respectively), the contrast is unambiguously one of occlusion, since stops and fricatives occur at exactly the same place of articulation. By parallelism, Trubetzkoy proposes that the same contrast should apply to the ambiguous cases, which leads to the conclusion that the minor place splits are phonologically irrelevant. The contrasts in the inventory can be pictured as in (13).

(13) Modern Greek: major place, voicing, occlusion $>$ minor place ${ }^{7}$

\begin{tabular}{|lc|c|c|c|}
\hline & Labial & Apical & Sibilant & Dorsal \\
voiceless stops & $\mathrm{p}$ & $\mathrm{t}$ & $\mathrm{ts}$ & $\mathrm{k}$ \\
voiceless fricatives & $\mathrm{f}$ & $\theta$ & $\mathrm{s}$ & $\mathrm{X}$ \\
voiced fricatives & $\mathrm{v}$ & ð & $\mathrm{z}$ & $\mathrm{y}$ \\
\hline
\end{tabular}

In French, however, Trubetzkoy (1969: 126) argues for a split labial series. "For in the entire French consonant system there is not a single phoneme pair in which the relation spirant : occlusive would occur in its pure form". Indeed, Trubetzkoy follows this analysis to its logical conclusion that there is no opposition between occlusives and spirants in French, because degree of occlusion cannot be regarded independently of position of articulation. Thus, Greek and French require a different ordering of the continuant feature relative to minor place features.

(14) French obstruents (based on Martinet 1964: 65)

\begin{tabular}{|c|c|c|c|c|c|c|}
\hline & $\frac{\sqrt{0}}{\frac{\pi}{\pi}}$ & 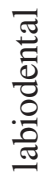 & 胥 & $\begin{array}{l}\frac{\bar{J}}{0} \\
\frac{0}{0} \\
\frac{D}{0}\end{array}$ & 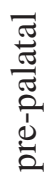 & $\begin{array}{l}\bar{z} \\
0 \\
0 \\
0 \\
0 \\
0 \\
0\end{array}$ \\
\hline voiceless & $\mathrm{p}$ & $\mathrm{f}$ & $\mathrm{t}$ & $S$ & $\check{S}$ & $\mathrm{k}$ \\
\hline voiced & $b$ & $\mathrm{~V}$ & d & $\mathrm{Z}$ & $\check{Z}$ & $\mathrm{~g}$ \\
\hline
\end{tabular}

7 I substitute phonetic transcription for Trubetzkoy's Greek letters.

8 As Trubetzkoy does not give a chart, I adapt this one from Martinet (1964), whose analysis is clearly influenced by Trubetzkoy. 
These analyses are inconsistent with Trubetzkoy's earlier discussion of bilateral oppositions in French. Whereas earlier he assumed that /t/ and /d/ were contrastively occlusive, according to his later analysis occlusion plays no role at all in the French consonant system. Moreover, in a hierarchical approach to contrastive specification, it is not at all clear that voicing is redundant for $/ \mathrm{n} /$, contrary to Trubetzkoy's assertion. For example, if [voiced] is ordered above [nasal], then the voicing contrast will include in its purview the nasal consonants as well, as shown in (15a). In this ordering, /d/ /n/ participate in a bilateral opposition, but $/ \mathrm{t} / \sim / \mathrm{d} / \mathrm{do}$ not. On the other hand, the features could be ordered as in (15b), in which case nasals are not specified for voicing, /d/ /n/ do not form a bilateral opposition, but $/ \mathrm{t} / \sim / \mathrm{d} / \mathrm{do}$.

(15) French dental obstruents and nasals:

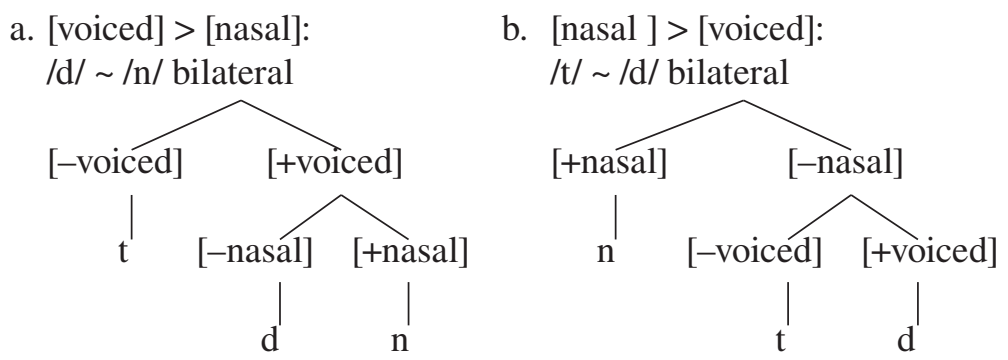

The tree diagrams in (15) show one important characteristic of specification by a top-down feature hierarchy: feature values that are logically redundant, such as [+voiced] for /n/, or [-nasal] for /t/, may still be designated as contrastive, if they are high enough on the hierarchy. A further difference from the previous method of determining contrastive features is that changes in the feature hierarchy can result in different contrastive specifications for the same inventory; the method based on fully specified minimal pairs always leads to the same contrastive specifications (where it works at all). Thus, the contrastive feature that distinguishes /p/ from /f/ in French is different from the one that distinguishes these phonemes in Greek; this result is not obtainable from making pairwise comparisons of fully specified segments.

\subsection{An algorithm for specifying contrasts by a feature hierarchy}

Let us consider a bit more explicitly how contrast is determined using a hierarchy of features. An algorithm corresponding to this idea, which we call 
the Successive Division Algorithm (Dresher 1998b, 2003), is given in (16). ${ }^{9}$ The basic idea is that we start by assuming that all sounds form one phoneme. This primordial allophonic soup is divided into two or more sets by whichever distinctive feature is selected first. We keep dividing up the inventory into sets, applying successive features in turn, until every set has only one member.

(16) Successive Division Algorithm (SDA)

a. In the initial state, all tokens in inventory I are assumed to be variants of a single member. Set $\mathrm{I}=\mathrm{S}$, the set of all members.

b. i) If $\mathrm{S}$ is found to have more than one member, proceed to (c).

ii) Otherwise, stop. If a member, $\mathrm{M}$, has not been designated contrastive with respect to a feature, $\mathrm{G}$, then $\mathrm{G}$ is redundant for $\mathrm{M}$.

c. Select a new $n$-ary feature, $\mathrm{F}$, from the set of distinctive features. ${ }^{10} \mathrm{~F}$ splits members of the input set, $\mathrm{S}$, into $n$ sets, $\mathrm{F}_{1}-\mathrm{F}_{n}$, depending on what value of $\mathrm{F}$ is true of each member of $\mathrm{S}$.

d. i) If all but one of $F_{1}-F_{n}$ is empty, then loop back to (c). ${ }^{11}$

ii) Otherwise, $\mathrm{F}$ is contrastive for all members of $\mathrm{S}$.

e. For each set $\mathrm{F}_{i}$, loop back to (b), replacing $\mathrm{S}$ by $\mathrm{F}_{i}$.

This algorithm solves the problems encountered by the Pairwise Algorithm. First, it adequately contrasts all members of an inventory, not just minimal pairs. Second, it is guaranteed to work in all inventories: it does not require any particular distribution of phonemes in the feature space. Third, it does not have to adopt auxiliary mechanisms for multiple logical redundancies; the ordering of the features in the hierarchy determines which features will be considered contrastive, and which redundant, in every case.

\subsection{The rise and fall of the contrastive hierarchy}

We have seen that Trubetzkoy's practice in Grundzüge does not point to a consistent method for determining contrastive features, but presupposes two

9 This algorithm is based on the method proposed by Jakobson and his colleagues in the 1950s (Jakobson, Fant and Halle 1952 and other works discussed in the next section). Dresher, Piggott and Rice (1994) call it the Continuous Dichotomy, echoing the "dichotomous scale" of Jakobson and Halle (1956).

10 I assume that the set of relevant distinctive features for a particular domain is given by some theory of that domain. By "new" feature I mean one that has not already been tried. Thus, the value of $\mathrm{F}$ changes every time this step reapplies (I assume some mechanism for keeping track of which features have already been tried, but do not specify it here).

11 That is, if all members of $\mathrm{S}$ have the same value of $\mathrm{F}$, then $\mathrm{F}$ is not contrastive in this set. 
different and incompatible approaches: one based on fully specified minimal pairs, and another based on feature ordering. It is perhaps noteworthy that in the cases where his analysis is accompanied with a clear empirical motivation, it tends to be consistent with the ordering approach, assuming a "certain hierarchy" of features.

We also observed that Jakobson (1949) implicitly relied on fully specified minimal pairs in his analysis of Serbo-Croatian. But like Trubetzkoy, Jakobson was not consistent in this regard, but used a hierarchical approach in other work. Indeed, as far as I know, he was the first person to explicitly argue for a feature hierarchy as a way of determining contrastive specifications. The feature hierarchy was given a prominent place in Jakobson, Fant and Halle (1952) and Jakobson and Halle (1956). The latter refer to this hierarchy as the "dichotomous scale", and adduce "several weighty arguments" in support of this hierarchical approach to feature specification. One argument had to do with information theory, based on work with Colin Cherry (Cherry, Halle and Jakobson 1953). Their second argument involves language acquisition. They suggest that distinctive features are necessarily binary because of the way they are acquired, through a series of "binary fissions". They propose (1956: 41) that the order of these contrastive splits is partially fixed, thereby allowing for certain developmental sequences and ruling out others.

The sequence in (17), for example, concerns oral resonance (primary and secondary place) features. Jakobson and Halle propose that a contrast between dental and labial consonants must be made before a contrast between narrow and wide vowels; following the emergence of this contrast, children may either make a further contrast in the set of narrow vowels, or elaborate contrasts in the consonantal system. As the sequence proceeds, more choices become available.

(17) Predicted acquisition sequences (Jakobson and Halle 1956: 41)

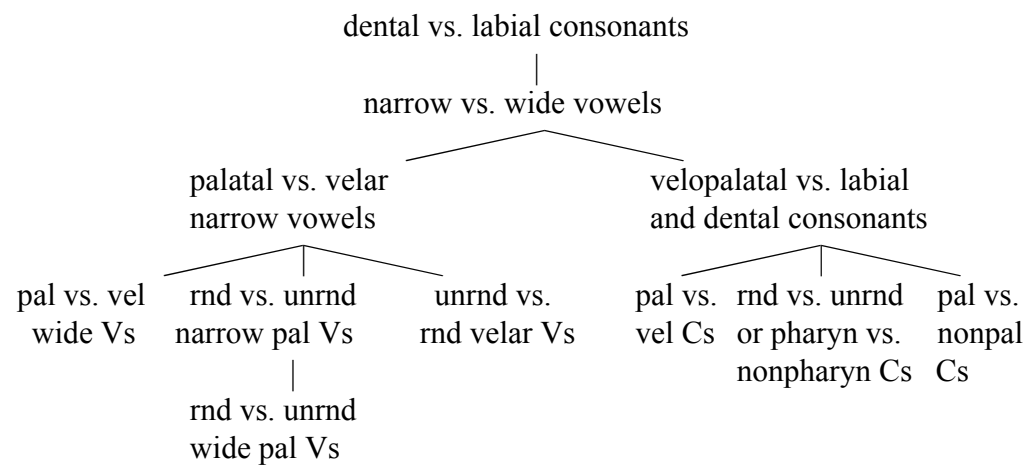


The notion of a feature hierarchy that governs the operative contrasts in a phonological inventory has been fruitfully applied in the field of child language, where it is a natural way of describing developing phonological inventories, along the lines set out by Jakobson and Halle (1956) (Pye, Ingram and List 1987, Ingram 1989, Levelt 1989, Dinnsen et al. 1990, Dinnsen 1992, Fikkert 1994). However, it has had a rockier fate in phonological theory itself.

Despite their arguments for it, the contrastive hierarchy was employed inconsistently by Jakobson and Halle in the late 1950s. Perhaps the inconsistency is due to their failure to arrive at a single universal hierarchy that could apply to all the languages they studied. It appeared in the "branching diagrams" of Halle (1959). The use of "branching diagrams" was challenged on various grounds by Stanley (1967) and subsequently virtually disappeared from the theory of generative phonology. Yet, that was not the end of the story for the contrastive hierarchy.

\section{Implicit hierarchies in phonological theory and descriptions}

Though he opposed the branching diagrams, Stanley (1967: 408) nevertheless observed that "there is obviously some kind of hierarchical relationship among the features which must somehow be captured in the theory." This intuition has continued to haunt phonological theory, popping up in diverse and sometimes unexpected ways.

The notion of a hierarchy of features is evident in various forms of markedness theory, starting with Chomsky and Halle (1968) and Kean (1980). Here, too, the emphasis has been on finding a single universal hierarchy, though such a quest has not been entirely successful. The same can be said for feature geometry (Clements and Hume 1995, Halle, Vaux and Wolfe 2000) which builds a fixed hierarchy directly into representations. Less obviously, versions of underspecification theory (Kiparsky 1982, 1985, Archangeli 1984, Steriade 1987) also can be shown to assume some notions of a feature hierarchy.

Apart from explicit discussions of phonological theory, feature hierarchies are often implicit in at least a partial way in the common practice of phonologists from a variety of theoretical backgrounds when they are presenting segmental inventories. Tables of segmental inventories are often arranged in descriptive grammars in ways that suggest that certain features have wider or narrower contrastive scope than others, which amounts to a partial feature hierarchy.

Compare, for example, the inventory tables of Siglitun, an Inuit (EskimoAleut) language spoken in the Canadian Arctic, and Kolokuma Ijo, an Ijoid (Niger-Congo) language spoken in Nigeria, given in (18) and (19), respective- 
ly. I present them as they are given in the sources (with some changes to the phonetic symbols but not to the arrangement). Note in particular the different placements of $/ 1 /$ and $/ j /$ in these charts. The chart of Ijo expresses a hierarchy in which the feature [continuant] has wider scope than such features as [sonorant] and [voiced], and [lateral] has wider scope than [nasal]. The Siglitun chart is not as overtly hierarchical, but it is clear that the feature [lateral] has very narrow scope, confined to making distinctions among apicals, whereas [nasal] is higher in the hierarchy. Apart from the nasals, the other sonorants are not set apart in Siglitun, suggesting that the feature [sonorant] is lower in the hierarchy than in Ijo.

(18) Siglitun consonants (Dorais 1990: 70) ${ }^{12}$

\begin{tabular}{|c|c|c|c|c|}
\hline & Bilabial & Apical & Velar & Uvular \\
\hline Stops & $\mathrm{p}$ & $\mathrm{t}$ & $\mathrm{k}$ & q \\
\hline Voiced fricatives & $\mathrm{V}$ & 1 & $\mathrm{y}$ & $\mathrm{R}$ \\
\hline Voiceless fricatives & & 4 & & \\
\hline Nasals & $\mathrm{m}$ & $\mathrm{n}$ & $\mathrm{y}$ & \\
\hline
\end{tabular}

(19) Consonant phonemes of Kolokuma Ijo (Williamson 1965) ${ }^{13}$

\begin{tabular}{|c|c|c|c|c|c|c|c|}
\hline & \multirow{2}{*}{\multicolumn{2}{|c|}{ Plosive }} & \multicolumn{5}{|c|}{ Continuant } \\
\hline & & & \multicolumn{2}{|c|}{ Fricative } & \multicolumn{3}{|c|}{ Sonorant } \\
\hline & \multirow{2}{*}{ Vl. } & \multirow{2}{*}{ Vd. } & \multirow{2}{*}{ Vl. } & \multirow{2}{*}{ Vd. } & \multicolumn{2}{|c|}{ Non-lateral } & \multirow{2}{*}{ Lateral } \\
\hline & & & & & Oral & Nasal & \\
\hline Labial & $\mathrm{p}$ & b & $\mathrm{f}$ & $\mathrm{V}$ & $\mathrm{w}$ & $\mathrm{m}$ & \\
\hline Alveolar & $\mathrm{t}$ & d & s & $\mathrm{z}$ & $\mathrm{r}$ & $\mathrm{n}$ & 1 \\
\hline Back & $\mathrm{k}$ & g & (h) & (y) & $\mathrm{j}$ & y & \\
\hline Labio-velar & $\mathrm{kp}$ & $\mathrm{gb}$ & & & & & \\
\hline
\end{tabular}

12 I have simplified Dorais's $j / d j$ and $s / c h$ to $j$ and $s$, respectively. As he makes clear, these are variants of single phonemes. Dorais does not usually indicate variants in his charts, and in related dialects in which /j/ has similar variants he lists only $j$. Therefore, I keep to the usual practice of representing a phoneme by one symbol.

13 I substitute $j$ for Williamson's $y$. Williamson notes that Back = palatal, velar or glottal, Vl. = voiceless, and Vd. = voiced. Williamson mentions that some speakers have a marginal phoneme $/ \mathrm{y} /$, but she omits it from the table. I have added it because it appears to be no less marginal than $/ \mathrm{h} /$, which is included. 
So pervasive is the hierarchical approach to inventories that we can find it even in the descriptive practice of those who explicitly argue against it. In $A$ Manual of Phonology, C.F. Hockett (1955: 173) reviews the different ways of construing the contrasts in the French obstruent system. He observes that place distinctions can make continuancy redundant (the solution favoured by Trubetzkoy and Martinet, shown in (14)); conversely, continuancy can be used to make minor place distinctions redundant (as in the analysis in (13) of Modern Greek). However, he continues: "Both of these decompositions of the French obstruents have the odor of pure game-playing..." He goes on to suggest that it is simply not possible to ever distinguish between features that are "determining" (that is, contrastive), and those that are "determined" (redundant).

Hockett's conclusion, however, is not consistent with his own practice in the rest of the Manual. If we can indeed make no distinctions between "determining" and "determined" features, it would be difficult to assign phonemic symbols to a set of allophones, let alone arrange them into neat schematic diagrams. But this Hockett does in his presentation of types of vowel and consonant systems.

For example, he observes (Hockett 1955: 84) that a 2x2 type of vowel system is widespread. He portrays such a system with the diagram in (20).

A 2x2 vowel system (Hockett 1955: 84)

\begin{tabular}{|ll|}
\hline $\mathrm{i}$ & $\mathrm{o}$ \\
$\mathrm{e}$ & $\mathrm{a}$ \\
\hline
\end{tabular}

As examples, Hockett cites Rutul (Caucasian), in which the high back vowel is sometimes rounded, sometimes not, depending on environment; Fox and Shawnee (Algonquian), where the low back vowel is usually unrounded, though rounded in certain environments; and a number of other languages. It is particularly telling that the schematic diagram (20), for which he cites no specific language, has /o/ rather than /u/ aligned in the same row with /i/, and /e/ rather than /æ/ in the same row as /a/. He adds, "we class Fox as a two-bytwo system despite the fact that the vowel classed as low back, /a/, is typically lower than that classed as low front, /e/". Though he lists no features, the arrangement in (20) can only mean that backness is the contrastive (determining) place/timbre feature, and that roundness is the redundant (determined) feature. The chart further indicates that there are only two phonological height classes, hence a single contrastive (determining) height feature; the phonetic height differences between $/ \mathrm{i} / \sim / \mathrm{o} /$ and $/ \mathrm{e} / \sim / \mathrm{a} /$ must therefore be considered 
redundant (determined). Thus, the chart indicates that it is not phonologically (i. e., contrastively) relevant that $/ \mathrm{o} / \mathrm{and} / \mathrm{a} /$ may be phonetically lower than $/ \mathrm{i} /$ and /e/, respectively; the choice of these symbols suggests that /o/ and /e/ might even be at the same height phonetically, though functioning phonemically at different heights. Indeed, the schematization in (20) appears to be specifically chosen to show how the contrastive structure of a vowel system can differ from its surface phonetic appearance. ${ }^{14}$

Hockett (1955) makes decisions like these about which features are contrastive and which redundant throughout his survey of vowel and consonant systems. To take one more example involving vowels, he writes that a $3+1$ system "is reported for Amahuaca" (21a), "though the /i/ may be lower than /i u/, placing Amahuaca rather with Ilocano and others" (21b). He observes that in the Filipino (Austronesian) languages represented by (21b), / // has fronted variants, and also higher central or back unrounded variants.

(21) Vowel systems: $3+1$ vs. 2+1+1 (Hockett 1955: 84-85)

a. Amahuaca

\begin{tabular}{|llll|}
\hline$i$ & & i & u \\
& & & \\
& & $a$ & \\
\hline
\end{tabular}

b. Ilocano

\begin{tabular}{|lll|}
\hline I & & U \\
& & \\
& $\partial$ & \\
& $\mathrm{a}$ & \\
\hline
\end{tabular}

It is not important, for the purposes of this discussion, whether Amahuaca (a Panoan language of Peru and Brazil) is as in (21a) or (21b). What is important is that Hockett believes it is meaningful to assign it to one or the other. If there is indeed no way to distinguish between determined and determining features, we could not represent Ilocano as in (21b), since this diagram implies that the determining features of $/ \partial /$, for example, are that it is central and mid, even though it has variants that are front and others that are high. Similarly, Amahuaca could not be represented as in (21a) if / $\mathbf{i} /$ is phonetically lower than /i u/ to any extent, because that means making a decision that its centrality and non-lowness are its contrastive features and its lower height relative to the other high vowels is a redundant feature.

14 In this regard, Hockett is following in the tradition of Sapir (1925: 37-51); as Sapir puts it, "And yet it is most important to emphasize the fact, strange but indubitable, that a pattern alignment does not need to correspond exactly to the more obvious phonetic one." 


\section{Conclusion}

I have argued that, despite the often-stated importance of contrast to phonological theory, methods for distinguishing between contrastive and redundant features in any given situation have been little discussed and seldom made explicit. The brief survey above has identified two different and incompatible methods for assigning contrastive features to segments that have been used intermittently in phonology. The first approach, based on fully-specified minimal pairs, has a certain intuitive appeal, but can be shown to be incapable of producing usable contrastive specifications in many situations. The second method, based on setting up a feature hierarchy in which the contrastive scope of features is determined by ordering, is a sounder method that can be applied to any phonological inventory. Thus, the main argument of this paper can be summarized as in (22).

(22) The Contrastive Hierarchy

Contrastive features are determined by establishing a feature hierarchy for a language and applying the Successive Division Algorithm.

It remains an empirical question whether this method of distinguishing between contrastive and redundant features, or any other method, is relevant to the operation of phonological systems. The cases discussed above suggest that contrast is important because contrastive features have a special role to play in phonological patterning. An explicit hypothesis based on this long-standing assumption is formulated as follows by Dresher and Zhang (2005):

(23) Contrast and phonological activity (Dresher and Zhang 2005) ${ }^{15}$

Only contrastive feature values are active in the (lexical) phonology.

The hypotheses in (22) and (23) are the subject of ongoing research in the project on Markedness and Contrast in Phonology at the University of Toronto (http://www.chass. utoronto.ca/ contrast/); see Avery and Rice (1989), Dresher (1998a, b, 2002, 2003), Dresher and Rice (2002), Dresher, Piggott, and Rice (1994), Hall (this volume), Rice (1993, 1997, 2002), and Rice and Avery (1995). Work in this framework also includes the dissertations by Avery (1996) on cross-linguistic voicing contrasts, Causley (1999) on segmental complexity and

15 Hall (2007: 20) calls this the Contrastivist Hypothesis, which he formulates as follows: "The phonological component of a language L operates only on those features which are necessary to distinguish the phonemes of L from one another." 
markedness in Optimality Theory, Dyck (1995) on phonetic and phonological patterning of Spanish and Italian vowels, Ghini (2001) on the phonology of Miogliola, Hall (2007) on phonological and phonetic aspects of the contrastivist hypothesis, with special application to Slavic languages, Walker (1993) on vowel harmony in Altaic, Wu (1994) and Zhou (1999) on Mandarin segmental phonology, and Zhang (1996) on Manchu-Tungusic languages; dedicated issues of the Toronto Working Papers in Linguistics (most recently Hall 2003 and Frigeni, Hirayama and Mackenzie 2005); and other references listed on the website.

\section{References}

Archangeli, Diana

1984 Underspecification in Yawelmani phonology and morphology. Ph. D. dissertation, MIT.

Archangeli, Diana

1988 Aspects of underspecification theory. Phonology 5: 183-207.

Avery, Peter

1996 The representation of voicing contrasts. Ph. D. dissertation, Department of Linguistics, University of Toronto.

Avery, Peter and Keren Rice

1989 Segment structure and coronal underspecification. Phonology 6: 179-200.

Causley, Trisha

1999 Complexity and Markedness in Optimality Theory. Ph. D. dissertation, Department of Linguistics, University of Toronto.

Cherry, E. Colin, Morris Halle and Roman Jakobson

1953 Toward the logical description of languages in their phonemic aspect. Language 29: 34-46. Reprinted in Roman Jakobson (1962), Selected Writings I, 449-463. The Hague: Mouton \& Co.

Chomsky, Noam

1964 Current issues in linguistic theory. In Jerry A. Fodor and Jerrold J. Katz (eds.), The Structure of Language, 50-118. Englewood Cliffs, NJ: Prentice-Hall.

Chomsky, Noam and Morris Halle

1956 On the logic of phonemic description. Paper presented at the M.I.T. Conference on Speech Communication, June 16, 1956.

Chomsky, Noam and Morris Halle

1968 The Sound Pattern of English. New York: Harper \& Row.

Clements, G. N. and Elizabeth V. Hume

1995 The internal organization of speech sounds. In John A. Goldsmith (ed.), Handbook of Phonology, 245-306. Oxford: Blackwell. 
Dinnsen, Daniel A.

1992 Variation in developing and fully developed phonetic inventories. In: Charles A. Ferguson, Lisa Menn and Carol Stoel-Gammon (eds.), Phonological Development: Models, Research, Implications, 191-210. Timonium, MD: York Press.

Dinnsen, Daniel A., Steven B. Chin, Mary Elbert and Thomas W. Powell

1990 Some constraints on functionally disordered phonologies: Phonetic inventories and phonotactics. Journal of Speech and Hearing Research 33: 28-37.

Dorais, Louis-Jacques

1990 Inuit Uqausiqatigiit: Inuit Languages and Dialects. Iqaluit: Arctic Col-

Dresher, B. Elan lege - Nunatta Campus.

1998a Child phonology, learnability, and phonological theory. In: Tej Bhatia and William C. Ritchie (eds.), Handbook of Language Acquisition, 299-346. New York: Academic Press.

Dresher, B. Elan

1998b On contrast and redundancy. Paper presented at the annual meeting of the Canadian Linguistic Association, Ottawa. Ms., Department of Linguistics, University of Toronto.

Dresher, B. Elan

2002 Determining contrastiveness: A missing chapter in the history of phonology. In Sophie Burelle and Stanca Somesfalean (eds.), Proceedings of the 2002 annual conference of the Canadian Linguistic Association, 82-93. Montreal: Département de linguistique et de didactique des langues, Université du Québec à Montréal.

Dresher, B. Elan

2003 Contrast and asymmetries in inventories. In Anna-Maria di Sciullo (ed.), Asymmetry in Grammar, Volume 2: Morphology, Phonology, Acquisition, 239-57. Amsterdam: John Benjamins.

Dresher, B. Elan and Keren Rice

2002 Markedness and the contrastive hierarchy in phonology. http://www. chass.utoronto.ca/ contrast/.

Dresher, B. Elan and Xi Zhang

2005 Contrast and phonological activity in Manchu vowel systems. Canadian Journal of Linguistics 50: 45-82.

Dresher, B. Elan, Glyne Piggott and Keren Rice

1994 Contrast in phonology: Overview. Toronto Working Papers in Linguistics 13: iii-Xvii.

Dyck, Carrie

1995 Constraining the phonology-phonetics interface, with exemplification from Spanish and Italian dialects. Ph. D. dissertation, Department of Linguistics, University of Toronto.

Fikkert, Paula

1994 On the Acquisition of Prosodic Structure (HIL Dissertations 6). Dordrecht: ICG Printing. 
Frigeni, Chiara, Manami Hirayama and Sara Mackenzie (eds.)

2005 Toronto Working Papers in Linguistics (Special Issue on Similarity in Phonology) 24. Toronto: Department of Linguistics, University of Toronto.

Ghini, Mirco

2001 Asymmetries in the Phonology of Miogliola. Berlin: Mouton de Gruyter.

Hall, Daniel Currie (ed.)

2003 Toronto Working Papers in Linguistics (Special Issue on Contrast in Phonology) 20. Toronto: Department of Linguistics, University of Toronto.

Hall, Daniel Currie

2007 The role and representation of contrast in phonological theory. $\mathrm{Ph}$. D. dissertation, Department of Linguistics, University of Toronto.

Hall, Daniel Currie this volume Prophylactic features and implicit contrast.

Halle, Morris

1959 The Sound Pattern of Russian: A Linguistic and Acoustical Investigation. The Hague: Mouton. Second printing, 1971.

Halle, Morris, Bert Vaux and Andrew Wolfe

2000 On feature spreading and the representation of place of articulation. Linguistic Inquiry 31: 387-444.

Hockett, Charles, F.

1955 A Manual of Phonology. Baltimore: Waverly Press.

Ingram, David

1989 First Language Acquisition: Method, Description and Explanation.

Jakobson, Roman

Cambridge: Cambridge University Press.

1949 On the identification of phonemic entities. Travaux du Cercle Linguistique de Copenhague 5: 205-213. Reprinted in Roman Jakobson (1962), Selected Writings I, 418-425. The Hague: Mouton \& Co.

Jakobson, Roman, C. Gunnar M. Fant and Morris Halle

1952 Preliminaries to speech analysis. MIT Acoustics Laboratory, Technical Report, No. 13. Reissued by MIT Press, Cambridge, Mass., Eleventh Printing, 1976.

Jakobson, Roman and Morris Halle

$1956 \quad$ Fundamentals of Language. The Hague: Mouton.

Kean, Mary-Louise

1980 The theory of markedness in generative grammar. Ph. D. dissertation, MIT. Reproduced by the Indiana University Linguistics Club, Bloomington, Indiana.

Kiparsky, Paul

1982 From cyclic to Lexical Phonology. In Harry van der Hulst and Norval Smith (eds.), The Structure of Phonological Representations (Part I), 131-176. Foris: Dordrecht. 
Kiparsky, Paul

1985 Some consequences of Lexical Phonology. Phonology Yearbook 2: $85-138$.

Levelt, C.C.

1989 An essay on child phonology. M. A. thesis, Leiden University.

Martinet, André

1964 Elements of General Linguistics. With a foreword by L.R. Palmer.

Translated by Elisabeth Palmer. Chicago: University of Chicago Press.

Pye, Clifton, David Ingram and Helen List

1987 A comparison of initial consonant acquisition in English and Quiché. In: Keith E. Nelson and Ann Van Kleeck (eds.), Children's Language (Vol. 6), 175-190. Hillsdale, NJ: Lawrence Erlbaum.

Rice, Keren

1993 A reexamination of the feature [sonorant]: The status of "sonorant obstruents". Language 69: 308-344.

Rice, Keren

1997 Japanese NC clusters and the redundancy of postnasal voicing. Linguistic Inquiry 28: 541-551.

Rice, Keren

2002 Vowel place contrasts. In Mengistu Amberber and Peter Collins (eds.),

Language Universals and Variation, 239-270. Westport, CT: Praeger.

Rice, Keren and Peter Avery

1995 Variability in a deterministic model of language acquisition: A theory of segmental elaboration. In: John Archibald (ed.), Phonological Acquisition and Phonological Theory, 23-42. Hillsdale, NJ: Lawrence Erlbaum.

Sapir, Edward

1925 Sound patterns in language. Language 1: 37-51. Reprinted in Martin Joos (ed.), Readings in Linguistics I, 19-25. Chicago: University of Chicago Press, 1957.

Saussure, Ferdinand de

1916/1972 Cours de linguistique générale. Publié par Charles Bally et Albert Sechehaye; avec la collaboration de Albert Riedlinger. Éd. critique

Stanley, Richard préparée par Tullio de Mauro. Paris: Payot.

1967 Redundancy rules in phonology. Language 43: 393-436.

Steriade, Donca

1987 Redundant values. In: Anna Bosch, Barbara Need and Eric Schiller (eds.), CLS 23: Papers from the 23rd Annual Regional Meeting of the Chicago Linguistic Society. Part Two: Parasession on Autosegmental and Metrical Phonology, 339-362. Chicago: Chicago Linguistic Society.

Trubetzkoy, N. S.

1969 Principles of Phonology. Berkeley: University of California Press. Translated by C. Baltaxe from Grundzüge der Phonologie. Göttingen: Vandenhoek \& Ruprecht, 1939. 
Tryon, D. T.

1970 An Introduction to Maranungku (Pacific Linguistics Series B, \#14). Canberra: Australian National University.

Walker, Rachel

1993 Contrastive specification and vowel harmony mechanisms in the Altaic languages. Forum paper (M. A. thesis), Department of Linguistics, University of Toronto.

Williamson, Kay

1965 A Grammar of the Kolokuma Dialect of Ijo. Cambridge: Cambridge University Press.

$\mathrm{Wu}$, Yuwen

1994 Mandarin segmental phonology. Ph. D. dissertation, Department of Linguistics, University of Toronto.

Zhang, Xi

1996 Vowel systems of the Manchu-Tungus languages of China. Ph. D. dissertation. University of Toronto.

Zhou, Hong

1999 Vowel systems in Mandarin languages. Ph. D. dissertation, Department of Linguistics, University of Toronto. 